\title{
PECULIARITIES OF PSYCHOLOGICAL WELL-BEING OF STUDENTS WITH DIFFERENT ETHNIC OWNERSHIP INCLUDED IN A UNIFORM EDUCATIONAL ENVIRONMENT OF THE UNIVERSITY
}

The work has been completed with the financial support of financial support by RFBR and SC RA (project № 20-513-05005 \20)

Tikhomirova E.V., Vishnevskaya O. N., Morozova D. N. (Kostroma State University, Kostroma, Russia) tichomirowa82@mail.ru

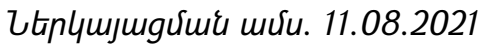
9pupunuर्ume uर्u. 23.08.2021

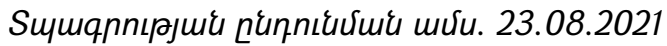

The article is devoted to the study of the peculiarities of psychological well-being and the specifics of understanding its indicators, barriers and resources among students of different ethnicity, included in the unified educational environment of the university. The first part of the study involved 300 students $(M=19.64$; $S D=2.61)$ and were interviewed about the semantics they put into their own psychological well-being, its indicators and barriers to achievement. The second part - 60 students: 30 Russian and 30 representatives of other ethnic groups, representatives of Asian culture. As a result, the authors came to the conclusion that along with general trends in understanding and experiencing psychological well-being among students of different ethno cultural groups who are in a single educational environment, there are also specific trends related to the mentality, culture, customs and the very specifics of the social situation of educational migration. Basically, students are moderately satisfied with their own lives, as they see a number of barriers that prevent them from fully feeling the state of psychological well-being.

Keywords: Psychological well-being, ethno cultural characteristics, students, educational migration, the multicultural environment of the university.

DOI: https://doi.org/10.46991/SBMP/2022.5.1.116

Вопросы, связанные с психологическим благополучием студентов, активно поднимаются в современных психологических исследованиях. Подчеркивается, что низкий уровень психологического благополучия негативно отражается на учебной мотивации, академической успеваемости, несомненно, влияет на успешность профессионального становления [7]. Более того, низкий уровень психологического благополучия может становиться фак- 
тором риска саморазрушающего поведения в юности [6]. Особенно остро это может проявляться в периоды, отягощенные высокой психологической и социальной нагрузкой, каким и является период обучения в вузе. В студенческие годы происходит не только профессиональное становление, но и фрормируются ценностные образования личности, определяющие жизненные цели [1, 76]. Этот период насыщен переживаниями, связанными с сепарационным пиком, травмой отделения, необходимостью самостоятельно принимать решения, часто менять привычную среду, в том числе, связанную с переездом не только в другой город, но и другую страну в целях получения высшего образования.

Мультикультурность - это тренд современного мира, который активно проникает и в сореру высшего образования, что отражается в наборе студентов или в тенденции вузов набирать студентов из ближнего зарубежья. В результате в Костромском Государственном университете учатся студенты таких национальностей, как китайцы, монголы, узбеки, таджики. Все эти студенты, в свою очередь, встают перед задачей адаптации к новой для себя социокультурной среде. Однако адаптивные программы, которые реализуются на базе университета, часто мало учитывают культурные особенности тех студентов, которые приезжают из-за рубежа. Причина этого - принятие универсальной единой природы психологического благополучия субъекта, которое обусловливается целым рядом субъективных и объективных факторов, таких как возраст, уровень жизни, возможности досуга, образование, физическая и эмоциональная безопасность, физическое и психическое здоровье. В тоже время необходимо учитывать опосредование благополучия этнокультурными факторами, которым уделяется достаточно много внимания в мировой науке. К примеру, исследование семантики счастья, благополучия в 30 странах мирах выявило специфику восприятия счастья человеком в зависимости от культуры, к которой он принадлежит: в одних странах большое значение уделяется внешним факторам, в других - ставится акцент на чувствах, которые испытывает человек [8]. Интересно, что в зависимости от культуры, религии, традиций отличаются личностные черты, которые приписываются счастливому человеку [10]. Ключевую роль здесь играют сложившиеся в этносе стереотипы, провозглашаемые ценности, в том числе, специфика отношения к счастью и благополучию как ценности. Подобные исследования актуализируют исследовательский поиск в области кросскультурных различий психологического благополучия субъекта.

Интенсификация академической миграции означает, что понимание этнических различий в психическом здоровье молодых людей становится все более важным в ряде стран. Для иностранных студентов новая культурная, образовательная, часто климатическая среда становится вызовом, требую- 
щим актуализации дополнительных ресурсов для постепенной адаптации и достижения равновесного состояния. Последнее напрямую связано с достижением психологического благополучия. Психологическое благополучие - это условие адаптивности студентов, что очень важно для тех, кто приезжает из ближнего зарубежья. В связи с этим, особую значимость приобретает попытка осмысления особенностей психологического благополучия студентов с разной этнической принадлежностью, но которые находятся в одной образовательной, социальной, культурной среде. К тому же, понимание особенностей психологического благополучия студентов с разной этнической принадлежностью позволит вузу более эффективно выстраивать деятельность по построению индивидуальной образовательной траектории и созданию социокультурных условий для их роста и личностного поиска.

Проблемный вопрос, которому посвящено исследование: существуют ли в поликультурной студенческой среде универсальные семантические единицы психологического благополучия, а также специфические особенности психологического благополучия студентов с разной этнической принадлежностью, но находящихся в едином образовательном пространстве? В исследовании было выдвинуто предположение, что существуют сходства и различия в показателях и понимании психологического благополучия у студентов с разной этнической принадлежностью, но находящихся в единой образовательной среде.

Для проверки выдвинутых гипотез и решения поставленных задач был сорормирован методический комплекс: Шкала субъективного счастья (С. Любомирски и Х. Леппер, 1999; адаптация Леонтьева Д.А., Е.Н. Осина, 2003) [3]; Шкала удовлетворённости жизнью (Satisfaction With Life Scale, 1985; в адаптации Д.А. Леонтьева, Е.Н. Осина, 2003) [5]; Шкала психологического благополучия К. Рифрф (Ryff Scales of Psychological Well-Being, 1989; адаптация Т.Д. Шевеленковой, П.П. Фесенко, 2005) [4], [2]; феноменологический интерпретативный анализ незаконченных предложений для семантики психологического благополучия, индикаторов и барьеров его достижения.

Выбор методического инструментария был обусловлен опорой на эвдемонистический подход, предполагающий изучение благополучия как модели переживания полноты существования, сопряженного с самоосуществлением. Важное методологическое значение приобретает представление френомена «психологического благополучия» в работах П.П. Фесенко и Т.Д. Шевеленковой, как целостного чувствования, выраженного в индивидуальном чувстве счастья, удовлетворенности собою и своим существованием, но кроме того взаимосвязанное с базисными человеческими ценностями и нуждами. Тут психологическое благополучие рассматривается как индивидуальное про- 
явление, переживание, что непосредственно зависит от организации внутренних оценок самого носителя этого волнения. Основываясь на концепции К. Риффр, П.П. Фесенко и Т.Д. Шевеленковой, подчеркнем, что любое чувство подразумевает сопоставление этого переживания с нормой, образцом, эталоном, которые содержатся в сознании самого переживающего лица в виде некоторого вида самооценки, самоотношения [2].

Методы исследования. В работе использовались методы общего познания, психодиагностические методы, а также статистические методы обработки данных, такие как: дескриптивная статистика, Т-критерий для двух независимых выборок, анализ различий (критерий Манна - Уитни), для анализа результатов незаконченных предложений использовался контент-анализ и критерий углового преобразования Фишера. Исследование проводилось с помощью гугл - формы и контактного интервью.

В связи с тем, что исследование проходило в два этапа, выборка также включает в себя несколько групп. В первой части исследования приняли участие 300 студентов Костромского государственного университета (в возрасте от 17 до 27 лет (M=19,64; SD=2,61), из которых 84,6\% были женского пола, 15,4\% - мужского) и были опрошены на предмет семантики, которую они вкладывают в собственное психологическое благополучие, его индикаторов и барьеров достижения. Во второй части исследования методом случайной выборки были отобраны 60 студентов (M=20.6; $\mathrm{Sd}=1.9)$ : 30 студентов по этнической принадлежности считающие себя русскими и 30 студентов - представителей иных этносов (китайцы, монголы, узбеки, таджики), как представители азиатской культуры. Группы рандомизировались по полу в эквиваленте 50\% женщин и 50\% мужчин. Для прохождения процедуры исследования им предлагалось заполнить методики на определение уровня психологического благополучия, счастья и удовлетворенности жизнью, а также проводилось полуструктурированное интервью. Все респонденты приняли участие в исследовании добровольно, им были обеспечены гарантии анонимности и конфиденциальности полученной информации.

Представление и обсуждение основных результатов исследования. На первом этапе студентам университета в количестве 300 человек было предложено ответить на три содержательных вопроса: «Я могу считать, что я достиг состояния психологического благополучия, когда...» (выявление индикаторов психологического благополучия), «Достичь состояния психологического благополучия мне мешает...» (выявление барьеров), «Чтобы достичь состояния психологического благополучия, мне необходимо...» (выявление ресурсов). Далее путем подсчета частоты встречаемости лексем были составлены рейтинговые иерархии (Таблица 1). 
Таблица 1.

Индикаторы, барьеры и ресурсы достижения психологического благополучия студентов (по результатам контент-анализа, $\mathrm{N}=300$ )

\begin{tabular}{|c|c|c|c|c|c|}
\hline $\begin{array}{l}\text { Индикаторы (кол-во } \\
\text { единиц) }\end{array}$ & Ранг & $\begin{array}{l}\text { Барьеры (кол-во } \\
\text { единиц) }\end{array}$ & Ранг & $\begin{array}{l}\text { Ресурсы } \quad \text { (кол-во } \\
\text { единиц) }\end{array}$ & Ранг \\
\hline $\begin{array}{l}\text { Достижение целей } \\
\text { (63) }\end{array}$ & 1 & Лень (64) & 1 & $\begin{array}{l}\text { Саморазвитие, } \\
\text { самореализация,работ } \\
\text { а над собой (95) }\end{array}$ & 1 \\
\hline $\begin{array}{l}\text { Удовлетворенность } \\
\text { собой и жизнью (50) }\end{array}$ & 2 & $\begin{array}{l}\text { Черты характера } \\
(40)\end{array}$ & 2 & Работа, труд (68) & 2 \\
\hline $\begin{array}{l}\text { Финансовая } \\
\text { независимость (39) }\end{array}$ & 3 & Ничего (33) & 3 & $\begin{array}{l}\text { Учеба, } \\
\text { образование }(58)\end{array}$ & 3 \\
\hline $\begin{array}{l}\text { Внутреннее } \\
\text { равновесие (36) }\end{array}$ & 4 & $\begin{array}{l}\text { Внешние условия } \\
(26)\end{array}$ & 4 & Наличие цели (49) & 4 \\
\hline $\begin{array}{l}\text { Построение семьи } \\
(27)\end{array}$ & 5 & $\begin{array}{l}\text { Низкая } \\
\text { самооценка (25) }\end{array}$ & 5 & Воля (23) & 5 \\
\hline Счастье (24) & 6 & $\begin{array}{l}\text { Эмоциональное } \\
\text { состояние (17) }\end{array}$ & 6 & $\begin{array}{l}\text { Материальные } \\
\text { ресурсы (18) }\end{array}$ & 6 \\
\hline Трудоустройство (20) & 7 & $\begin{array}{l}\text { Проявления } \\
\text { страхов (16) }\end{array}$ & 7 & $\begin{array}{l}\text { Близкие отношения } \\
\text { (16) }\end{array}$ & 7 \\
\hline Окончание учебы (13) & 8 & Финансы (15) & 9 & $\begin{array}{l}\text { Психологический } \\
\text { комфорт (14) }\end{array}$ & 8 \\
\hline Обретение жилья (11) & 9 & Другие люди (15) & 9 & $\begin{array}{l}\text { Собственная семья } \\
\text { (12) }\end{array}$ & 9 \\
\hline $\begin{array}{l}\text { Сепарация } \\
\text { родителей (8) }\end{array}$ & 10 & $\begin{array}{l}\text { Отсутствие } \\
\text { мотивации (15) }\end{array}$ & 9 & $\begin{array}{l}\text { Вера в себя и свои } \\
\text { силы (11) }\end{array}$ & 10 \\
\hline
\end{tabular}

Анализ полученных результатов дает основание полагать, что материальные аспекты благополучия у студентов не возведены в абсолют. Несмотря на то, что финансовая независимость, обретение собственного жилья входят в 10 первых ранговых позиций, то есть являются достаточно значимыми, в тоже время доминирующее количество индикаторов лежит в экзистенциальной плоскости, относится к смысловой мотивационно-ценностной сфрере. Так, наиболее часто встречаемыми стали индикаторы, связанные с достижением целей, состояния удовлетворенности собой и жизнью, состояния внутреннего равновесия, гармонии, счастья, построением собственной семьи и трудоустройством. Большинство респондентов указывало, что финансовая успешность играет опосредующую роль, так как расширяет рамку личных возможностей, позволяет быстрее достигать поставленных целей и 
задач. При определении ресурсов достижения благополучия материальная составляющая также не стала доминирующей - 6\% индикаторов. На первый план выходят личностные, внутренние ресурсы: саморазвитие, работа над собой, способность трудиться, знания, наличие целей, внутренний психологический комфорт, вера в себя. Направленность на свое внутреннее Я, понимание себя и своих возможностей, обретение согласия с самим собой, самоуважение рассматривается студентами как необходимый предиктор и ресурс обретения психологического благополучия. Такая позиция согласуется с личностной оценкой барьеров достижения благополучия, к которым респонденты чаще всего относят то, что является частью их личности и непосредственно связано с необходимостью самопреодоления: негативные личностные качества, среди которых особенно часто упоминалась лень, темперамент, закрытость новому опыту, пассивность, нерешительность, отсутствие веры в свои возможности, низкая самооценка, социальные страхи и многое другое. Внешние барьеры также упоминаются студентами, но, в отличие от внутренних, личностных, они отличаются высоким уровнем обобщения («условия, независящие от меня, проблемы, непредвиденные обстоятельства»), респонденты испытывают трудности при их идентификации, что может говорить о том, что на самом деле их негативное влияние не велико.

Для определения этнокультурной специфики восприятия благополучия студентами методом случайной выборки были отобраны 60 студентов $(M=20.6 ; \mathrm{Sd}=1.9): 30$ студентов по этнической принадлежности считающие себя русскими, и 30 студентов - представителей иных этносов (китайцы, монголы, узбеки, таджики), представители азиатской культуры, владеющие русским языком.

По результатам стандартизированных опросных методик на определение индекса счастья, удовлетворенности жизнью и психологического благополучия не было выявлено статистически значимых различий между данными группами. При этом, уровень счастья в совокупной выборке лежит в диапазоне средних значений $(\mathrm{M}=18.8 ; \mathrm{Sd}=4.62)$, т.е. независимо от этнокультурной принадлежности студентов, в целом, они воспринимают жизнь достаточно позитивно, но в тоже время есть дефицитарные зоны в их психологическом и событийном пространстве, которые требуют осмысления и наполнения для достижения ощущения полного счастья. Анализ результатов по шкале удовлетворенности показал, что средний показатель по выборке всех студентов равен $\mathrm{M}=19.3$; $\mathrm{Sd}=5.8$, что также соответствует средним нормативным значениям на выборке стандартизации. При этом, важно отметить, что разброс значений достаточно большой (Min=9, Max=32), т.е. есть не мало студентов, которые полностью удовлетворены своей жизнью, так и те, кто испытывает определенные трудности, неоднозначные эмоции, имеет 
стремление что-то изменить в своей жизни. Анализ результатов опросника «Шкала психологического благополучия» показал, что показатели либо соответствуют области средних значений, либо незначительно ниже. Наиболее выражены показатели следующих шкал: «Личностный рост» (мужчины $M=61.1 ; \mathrm{SD}=11.6$; женщины $\mathrm{M}=64.9 ; \mathrm{SD}=11.3$ ), «Цели в жизни» (мужчины $\mathrm{M}=60.3 ; \mathrm{SD}=8.6$; женщины $\mathrm{M}=58.8 ; \mathrm{SD}=7.9$ ). Молодые люди находятся в поиске себя, выстраивают взаимоотношения на качественно ином уровне, участвуют в общественных мероприятиях. Их жизнь наполнена смыслом, в ней присутствует внятный и понятный ориентир - получение образования. В то же время студенты еще не до конца понимают, что их ждет на жизненном пути, не завершен и процесс автономизации от родителей, им все так же нужна их поддержка, они испытывают материальные трудности независимо от этнокультультурной принадлежности.

Отсутствие статистически значимых различий между независимыми этнокультурными группами может быть связано с тем, что в данный конкретный момент, в процессе своего обучения они находятся в одном социальном контексте, живут по общим правилам и нормам, принятым в данном обществе, также играет роль изначальная поликультурность российского общества. Чтобы уточнить полученные в ходе тестирования данные, мы включили в свое исследование полуструктурированное интервью, открытые вопросы которого направлены на пояснение того, что является благополучием для студентов, а также на определение барьеров и ресурсов его достижения (Табл. 2, Табл. 3).

Таблица 2.

Частота встречаемости ответов на вопрос «Благополучие для меня это....» у представителей разных этнокультурных групп (N1=30; N2=30)

\begin{tabular}{|c|c|c|c|}
\hline Категория & Русские & $\begin{array}{l}\text { Представители других } \\
\text { этнокультурных групп }\end{array}$ & $\begin{array}{l}\varphi^{*} э м п \text { - значение } \\
\text { критерия Фишера }\end{array}$ \\
\hline Материальный достаток & $30 \%$ & $13.3 \%$ & 2.91 \\
\hline $\begin{array}{l}\text { Уверенность в будущем и } \\
\text { ощущение спокойствия }\end{array}$ & $16.7 \%$ & $33,3 \%$ & 2.74 \\
\hline $\begin{array}{l}\text { Удовлетворенность } \\
\text { потребностей }\end{array}$ & $20 \%$ & $26.7 \%$ & - \\
\hline $\begin{array}{l}\text { Духовное развитие и } \\
\text { душевное состояние }\end{array}$ & $23.3 \%$ & $46.7 \%$ & 3.52 \\
\hline
\end{tabular}

Результаты качественного анализа ответов респондентов на вопрос о том, что для них благополучие, показал, что частота встречаемости наиболее популярных ответов в группах значимо отличается. Материальный достаток определяет суть благополучия у русских студентов значимо выше, чем у 
представителей азиатской культуры. В свою очередь, у последних наиболее важное значение приобретают духовное развитие, состояние души, ощущение умиротворенности, спокойствия и уверенность в завтрашнем дне. В равной степени у студентов КГУ наблюдается удовлетворенность потребностей. Полученные отличия можно объяснить сутью самой восточной культуры, ее изначальной диалектичностью, обращенностью к внутреннему миру человека. В то же время, стоит отметить, что превалирующие по частоте встречаемости категории анализа совпадают у обеих групп, образуя лишь своеобразие в рамках иерархии рангов. В современном мире практически не осталось самобытной культуры, все находятся в одном информационном пространстве, социализируются в одном образовательном учреждении.

Таблица 3.

Частота встречаемости ответов на вопрос «Достигнуть благополучия мне помогает...» у представителей разных этнокультурных групп (N1=30; N2=30)

\begin{tabular}{|c|c|c|c|}
\hline Категория & Русские & $\begin{array}{l}\text { Представители других } \\
\text { этнокультурных групп }\end{array}$ & $\begin{array}{l}\varphi^{*} э м п \text { - значение } \\
\text { критерия Фишера }\end{array}$ \\
\hline Поддержка близких & $20 \%$ & $63.3 \%$ & 6.46 \\
\hline Искусство и религия & $6.7 \%$ & $13.3 \%$ & - \\
\hline $\begin{array}{l}\text { Удовлетворение витальных } \\
\text { потребностей }\end{array}$ & $10 \%$ & $10 \%$ & - \\
\hline Мировоззрение & $6.7 \%$ & $6.7 \%$ & - \\
\hline Мотивация & $6.7 \%$ & $10 \%$ & - \\
\hline Целеустремленность & $30 \%$ & $26.7 \%$ & - \\
\hline
\end{tabular}

Анализируя полученные результаты по вопросу, связанному с ресурсами достижения благополучия, важно отметить, что на помощь близких, семьи и родных в нашей выборке ориентируются чаще всего носители восточной культуры. Возможно, это объясняется тем, что в этих культурах важна ценность семьи, ее общность. Также следует учитывать, что оторванность от дома, проживание на территории другого государства актуализирует потребность в близких людях. Поддержание связи с родными ограждает от ощущения одиночества, дает силы для успешного функционирования в чужеродном социальном и культурном пространстве.

При анализе ответов на вопрос о барьерах достижения благополучия студенты обеих этнокультурных групп дали схожие ответы: особенности личности, материальные трудности и условия жизни. Интересно, что отсутствие преград для достижения благополучия чаще всего отмечали иностранные студенты. Ответы же русских студентов были более разнообразными, они в 
большей степени ссылались на внешние препятствия. Это согласуется с данными зарубежных ученых, которые выявили, что опосредует этнокультурные различия в показателях благополучия и счастья также и само отношение к афрфекту. В незападных культурах, в том числе у русских, положительные эмоции ценятся меньше, люди не склонны ими делиться с другими людьми [9]. Русские более пессимистично настроены и чаще склонны видеть препятствия, нежели пути решения.

Корреляционный анализ показал, что существует специфика связей показателей благополучия в разных этнокультурных группах. Так, в русской выборке студентов была выявлена значимая прямая связь между удовлетворенностью жизнью и управлением средой $(R=0.53 ; p=0.04)$, а шкала субъективного счастья положительно коррелирует с самопринятием ( $R=0.6$; $\mathrm{p}=0.02)$. У представителей других национальностей ощущение субъективного счастья положительно связано с удовлетворенностью жизнью $(\mathrm{R}=0.67$; $p=0.01)$, позитивными отношениями $(R=0.66 ; p=0.01)$ и управлением средой $(R=0.54 ; p=0.04)$. Чем позитивнее складываются отношения с другими людьми, есть ощущение поддержки, тем острее ощущение субъективного счастья у иностранных студентов, что только подтверждает данные интервьюирования.

Таким образом, наряду с общими тенденциями в понимании и переживании психологического благополучия у студентов разных этнокультурных групп, находящихся в единой образовательной среде, существуют и специфричные характеристики, связанные с менталитетом, культурой, национальными обычаями, а также самой спецификой социальной ситуации образовательной миграции. В основном, студенты в средней степени удовлетворены собственной жизнью, так как усматривают ряд барьеров, препятствующих в полной мере почувствовать состояние психологического благополучия: материальные трудности, проблемы, связанные с организацией собственной деятельности, с самоорганизацией, с той частью их личности, что требует саморазвития и самопреодоления. Для достижения благополучия студенты азиатских культур больше всего полагаются на опору, на ближайшее окружение, на поддержку семьи, друзей, русские студенты более ориентированы на самих себя.

\section{Литература}

1. Русина С. А. Психологическое благополучие студентов с разным уровнем ролевой самооценки. Вестник ЮУрГУ. Серия «Психология». 2015. Т. 8, № 4. с. 76-83.

2. Шевеленкова Т. Д., Фесенко П.П. Методика исследования психологического благополучия личности. М., 2005. 
3. Lyubomirsky S., Lepper H. S. (1999). A measure of subjective happiness: Preliminary reliability and construct validation. Social Indicators Research, 46 (2), pp. 137-155.

4. Ryff C. (1989). Happiness is everything, or is it? Explorations on the meaning of psychological well-being. Journal of Personality and Social Psychology, 57, pp.1069-1081.

5. Diener, E., Emmons, R. A., Larsen, R. J., \& Griffin, S. (1985). The Satisfaction with Life Scale. Journal of personality assessment, 49 (1), pp. 71-75.

https://doi.org/10.1207/s15327752jpa4901_13, https://pubmed.ncbi.nlm.nih.gov/16367493.

6. Bewick B., Koutsopoulou G., Miles J., Slaa E. \& Barkham M. (2010) Changes in undergraduate students' psychological well-being as they progress through university. Studies in Higher Education, 35:6, 633-645, DOI: 10.1080/03075070903216643 https://www.tandfonline.com/doi/full/10.1080/03075070903216643?src $=$ recsys

7. Bantjes J.R., Kagee A., McGowan T. \& Steel H. (2016) Symptoms of posttraumatic stress, depression, and anxiety as predictors of suicidal ideation among South African university students. Journal of American College Health, 64:6, pp. 429-437,

DOI: 10.1080/07448481.2016.1178120, https://www.tandfonline.com/doi/full/10.1080/07448481.2016.1178120.

8. Oishi, Shigehiro \& Graham, Jesse \& Kesebir, Selin \& Galinha, Iolanda. (2013). Concepts of Happiness Across Time and Cultures. Personality \& social psychology bulletin. 39. pp. 559-577. $10.1177 / 0146167213480042$.

https://www.researchgate.net/publication/236228372_Concepts_of_Happ iness_Across_Time_and_Cultures.

9. Sheldon, K. M., Titova, L., Gordeeva, T. O., Osin, E. N., Lyubomirsky, S., \& Bogomaz, S. (2017). Russians inhibit the expression of happiness to strangers: Testing a display rule model. Journal of $\begin{array}{llll}\text { CrossCultural Psychology, 48, } & \text { 48. }\end{array}$ doi:10.1177/0022022117699883

https://journals.sagepub.com/doi/abs/10.1177/0022022117699883

10.Suh, E. M., \& Choi, S. (2018). Predictors of subjective well-being across cultures. In E. Diener, S. Oishi, \& L. Tay (Eds.), Handbook of well-being. Salt Lake City, UT: DEF Publishers. DOI:nobascholar.com https://www.nobascholar.com/chapters/45. 


\section{ОСОБЕННОСТИ ПСИХОЛОГИЧЕСКОГО БЛАГОПОЛУЧИЯ СТУДЕНТОВ С РАЗНОЙ ЭТНИЧЕСКОЙ ПРИНАДЛЕЖНОСТЬЮ, ВКЛЮЧЕННЫХ В ЕДИНУЮ ОБРАЗОВАТЕЛЬНУЮ СРЕДУ ВУЗА}

Исследование выполнено при финансовой поддержке РФФИ и КН РА (проект № 20-513-05005\20)

Тихомирова Е.В., Вишневская О.Н., Морозова Д.Н. (Костромской государственный университет, Кострома, Россия)

Статья посвящена исследованию особенностей психологического благополучия и специфики понимания его индикаторов, барьеров и ресурсов у студентов с разной этнической принадлежностью, включенных в единую образовательную среду вуза. Исследование выполнено на стыке номотетического и идеографического подходов. В первой части исследования приняли участие 300 студентов ( $M=19,64 ; \mathrm{SD}=2,61)$, которые были опрошены на предмет семантики, которую они вкладывают в собственное психологическое благополучие, понимания его индикаторов и барьеров достижения. Во второй части исследования участвовали 60 студентов: 30, считающих себя русскими, и 30 представителей иных этносов, представителей азиатской культуры. В результате авторы пришли к выводу, что наряду с общими тенденциями в понимании и переживании психологического благополучия у студентов разных этнокультурных групп, находящихся в единой образовательной среде, существуют и специфичные, связанные с менталитетом, культурой, обычаями и самой спецификой социальной ситуации образовательной миграции. В основном, студенты в средней степени удовлетворены собственной жизнью, так как усматривают ряд барьеров, препятствующих в полной мере почувствовать состояние психологического благополучия.

Ключевые слова: психологическое благополучие, этнокультурные особенности, студенты, образовательная миграция, поликультурная среда вуза. 